Original Article

\title{
Metabolic profiles for the pyrrolizidine alkaloid neopetasitenine and its metabolite petasitenine in humans extrapolated from rat in vivo and in vitro data sets using a simplified physiologically based pharmacokinetic model
}

\author{
Mayu Yanagi, Yusuke Kamiya, Norie Murayama, Kaito Banju, Makiko Shimizu \\ and Hiroshi Yamazaki
}

Showa Pharmaceutical University, Machida, Tokyo 194-8543, Japan

(Received June 5, 2021; Accepted June 28, 2021)

\begin{abstract}
Naturally occurring food substances may constitute safety hazards. The risks associated with plant-derived pyrrolizidine alkaloids have been extensively evaluated. Petasites japonicus (common Japanese name, fuki) is a widely consumed water-soluble pyrrolizidine alkaloid-producing plant. In this study, neopetasitenine (acetylfukinotoxin) was selected as a model food substrate (for which human pharmacokinetics were estimated) because of its high concentration in fuki, along with petasitenine (fukinotoxin), its carcinogenic deacetylated metabolite. Although neopetasitenine was rapidly absorbed and converted to petasitenine after oral administration of $1.0 \mathrm{mg} / \mathrm{kg}$ in rats, petasitenine was slowly cleared from plasma. Forward dosimetry was conducted using in silico simplified physiologically based pharmacokinetic (PBPK) modeling formulated on experimental pharmacokinetic rat data. From $\sim 2 \mathrm{hr}$ after the oral administration of neopetasitenine in rats, the plasma concentrations of petasitenine were higher than those of neopetasitenine under the present conditions. A human PBPK model was established following an allometric scaling approach applied to rat parameters (without considering interspecies factors) to estimate human intrinsic hepatic clearances from empirical rat values. Human in silico neopetasitenine and petasitenine plasma concentration curves were simulated after daily oral administrations of 3.0 and $1.3 \mathrm{mg} / \mathrm{kg}$ neopetasitenine. These doses were taken from reported acute/short-term cases of pyrrolizidine alkaloid toxicity. In vitro hepatotoxicity of neopetasitenine and petasitenine was caused by their high concentrations in the medium for human hepatocyte-like cell line HepaRG cells as an index of lactate dehydrogenase leakage. Neopetasitenine was estimated to be rapidly absorbed and converted to deacetylated carcinogenic petasitenine, even after hepatotoxic doses of $1.0 \mathrm{mg} / \mathrm{kg}$ in humans. If the water-soluble pyrrolizidine alkaloid-producing plant $P$. japonicus were daily consumed as food, current simulation results suggest that dangerous amounts of deacetylated petasitenine could be continuously present in human plasma.
\end{abstract}

Key words: PBPK modeling, Allometric scaling, Acetylfukinotoxin, Fukinotoxin

\section{INTRODUCTION}

Traditional herbal medicines are naturally occurring, plant-derived substances that undergo minimal industrial processing and are widely used. Some of these medicinal plants are also used as food, but may constitute safety hazards. The risks of pyrrolizidine alkaloids in plants have been extensively evaluated (Chen et al., 2010; EFSA, 2011). Some plant-derived pyrrolizidine alka- loids have reportedly induced liver toxicity (Neuman et al., 2015). The lowest known doses associated with acute/short-term/long-term toxicity in humans have been reported as $3 \mathrm{mg}$ pyrrolizidine alkaloids $/ \mathrm{kg}$ body weight per day (exposure of a boy for a 4-day period, lethal outcome), $0.8-1.7 \mathrm{mg}$ pyrrolizidine alkaloids $/ \mathrm{kg}$ per day (exposure of a girl for a 2-week period, hepatic venoocclusive disease), and $15 \mu \mathrm{g}$ pyrrolizidine alkaloids $/ \mathrm{kg}$ per day (exposure for a 6-month period, hepatic veno-

Correspondence: Hiroshi Yamazaki (E-mail: hyamazak@ac.shoyaku.ac.jp) 
occlusive disease) (EFSA, 2011). Investigation of the alkaloidal constituents of Petasites japonicus (butterbur, common Japanese name fuki; Asteraceae) in the 1970s led to the identification of pyrrolizidine alkaloids (Kitajima et al., 2019). However, the toxicokinetics of these pyrrolizidine alkaloids in experimental animals have not been extensively determined, except for some limited cases of alkaloids (Wang et al., 2011). For these reasons, the consumption of certain plants or foods containing pyrrolizidine alkaloids is restricted in some countries.

The application of full or simplified physiologically based pharmacokinetic (PBPK) modeling has been recommended for interpreting toxicity screening data for general food chemicals (Sweeney et al., 2010; Rietjens et al., 2008; Vassallo et al., 2004). P. japonicus is a watersoluble pyrrolizidine alkaloid-producing plant and is consumed as a wild vegetable or used in folk medicine in Japan. In recent years, $P$. japonicus has sometimes been eaten without removing the harmful alkaloids by extensive boiling in water. In this study, neopetasitenine (acetylfukinotoxin) (Kiyoyuki et al., 1976) was selected as the model substrate for which the pharmacokinetics would be estimated because it is the major form of pyrrolizidine alkaloid in P. japonicus and is present in high concentrations, along with its carcinogenic deacetylated metabolite, petasitenine (fukinotoxin) (Hirono et al., 1977, 1979) (Fig. 1A). To underline the effectiveness and simplicity of PBPK models compared with complicated full multiple-compartment models, we created a simplified modeling system that uses a mixture of algorithms utilizing empirical data and/or literature resources (Kamiya et al., 2019, 2020a; Miura et al., 2019a, 2019b).

The current study focused on forward dosimetry assessments of neopetasitenine and petasitenine concentrations by setting up a human PBPK model from limited information. To the best of our knowledge, no reports are available in the literature relating to hepatotoxicity of the selected model substrate neopetasitenine. Using recognized species allometric scaling factors, the pharmacokinetic profiles of the selected food alkaloid neopetasitenine after virtual oral administrations were modeled in humans based on the finally observed plasma levels in rat studies, in which the major biotransformation of neopetasitenine to petasitenine was confirmed. By using forward dosimetry after virtual oral administrations of food-derived substances, we describe here the in silico human plasma levels of neopetasitenine and petasitenine according to our simplified modeling strategy after daily doses likely associated with acute/short-term toxicity in humans.

\section{MATERIALS AND METHODS}

\section{In vivo and in vitro metabolic study}

Sprague-Dawley rats (three males, 7 weeks old, Charles River Laboratory, Tokyo, Japan) and rat liver microsomes and $9000 \times g$ supernatant liver fractions (S9) prepared previously (Miura et al., 2020a, 2020b) were used. This study was approved by the Institutional Animal Care and Use Committees of Shin Nippon Biomedical Laboratories and Showa Pharmaceutical University. Blood samples $(100 \mu \mathrm{L})$ were collected from rats at times in the range $0.083-8.0 \mathrm{hr}$ after single oral doses $(1.0 \mathrm{mg} / \mathrm{kg})$ of neopetasitenine (CAS No 6040951-0) or petasitenine (CAS No 60102-37-6) obtained from Nagara Science, Gifu, Japan. The plasma samples and in vitro culture media or reaction mixtures (described below) were treated with an equal volume of methanol, and the aqueous supernatant was centrifuged at $2000 \times g$ for $10 \mathrm{~min}$ at $4^{\circ} \mathrm{C}$ and evaluated using liquid chromatography (LC)-tandem mass spectrometry.

Quantitative analyses of neopetasitenine and petasitenine were performed using a Xevo TQ-XS tandem mass analyzer (Waters, Milford, MA, USA), in electrospray positive ionization mode, directly coupled to a Shimadzu LC-30AD system equipped with an octadecylsilane $\left(\mathrm{C}_{18}\right)$ column (YMC-Triart, $3 \mu \mathrm{m}, 2.0 \mathrm{~mm} \times 150 \mathrm{~mm}$, YMC, Kyoto, Japan) maintained at $40^{\circ} \mathrm{C}$. For LC, solvent A was methanol and solvent B was $10 \mathrm{mM}$ ammonium acetate in water. The following gradient program was used with a flow rate of $0.30 \mathrm{~mL} / \mathrm{min}$ : 0-5.5 min, linear gradient from $5 \% \mathrm{~A}$ to $60 \% \mathrm{~A}(\mathrm{v} / \mathrm{v}) ; 5.6-7.0 \mathrm{~min}$, hold at $100 \% \mathrm{~A}$; and 7.1-9.0 $\mathrm{min}$, hold at 5\% A. The retention times of neopetasitenine and petasitenine were 5.1 and $3.7 \mathrm{~min}$, respectively. Neopetasitenine and petasitenine were quantified using the $m / z 424 \rightarrow 122$ transition and the $m / z \quad 382 \rightarrow 168$ transition, respectively. Under the present conditions, neopetasitenine and petasitenine levels in plasma were measurable $(\geq 1.0 \mathrm{ng} / \mathrm{mL})$ or detectable $(\geq 0.10 \mathrm{ng} / \mathrm{mL})$ with the prepared LC samples $(1.0 \mu \mathrm{L})$.

Permeability coefficients were estimated based on time-dependent in vitro absorption from the apical to the basal sides of in vitro human intestinal Caco-2 monolayers, as described previously (Kamiya et al., 2020b). In vitro elimination rates of substrates catalyzed by rat or human pooled liver microsomes or liver S9 fractions (Corning Life Sciences, Woburn, MA, USA) were measured using $\mathrm{LC}$ with ultraviolet detectors or tandem mass spectrometry with an analytical reversed-phase column. To evaluate the elimination of neopetasitenine and petasitenine, substrates $(10 \mu \mathrm{M})$ were incubated with liver microsomes or S9 fractions $(1.0 \mathrm{mg}$ protein $/ \mathrm{mL}$ ) and 


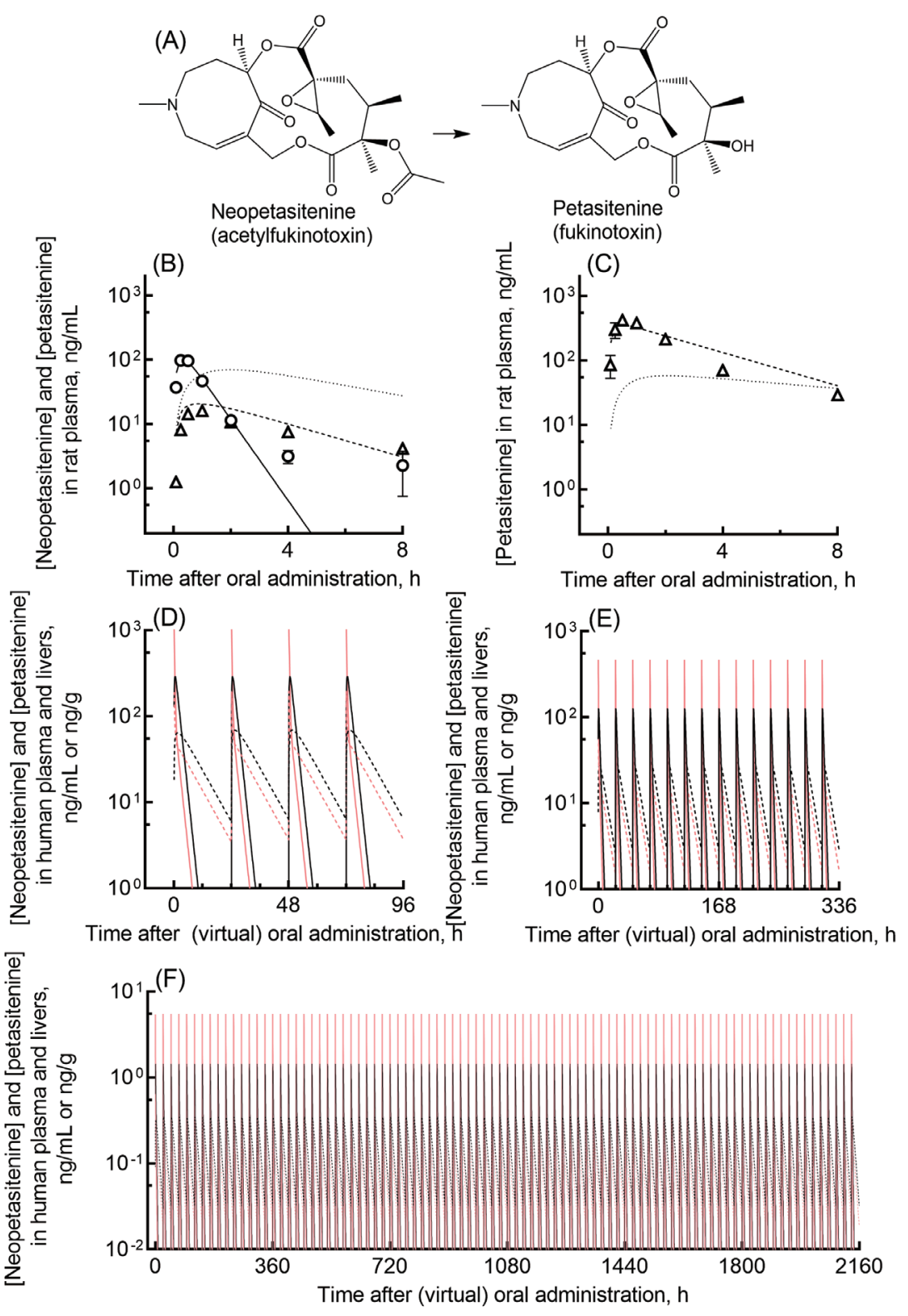

Fig. 1. Metabolic pathway from neopetasitenine to petasitenine (A), estimated plasma or hepatic concentrations of neopetasitenine/ petasitenine (B), petasitenine in rats (C), and neopetasitenine/petasitenine in humans (D-F). The observed values in plasma for neopetasitenine (circles) and petasitenine (triangles) are shown after single oral doses of $1.0 \mathrm{mg} / \mathrm{kg}$ of neopetasitenine (B) and petasitenine (C) in rats. In panels B and C, dotted lines were created by the PBPK model using parameters $\left(k_{\mathrm{a}}, V_{1}\right.$, and $C L_{\mathrm{h} \text {,int }}$ ) generated by in silico machine learning without any reference to experimental pharmacokinetic data in rats. Lines show the rat $(\mathrm{B}, \mathrm{C})$ and human (D-F) PBPK model results plasma (in black) or hepatic (in red) concentrations of for neopetasitenine (solid lines) and petasitenine (dashed lines) after virtual single oral doses of $1.0 \mathrm{mg} / \mathrm{kg}$ of neopetasitenine (B) and petasitenine (C) for rats and multiple oral daily doses of $3.0 \mathrm{mg} / \mathrm{kg}$ (D) for 4 days, $1.3 \mathrm{mg} / \mathrm{kg}$ (E) of neopetasitenine for 14 days, and $0.015 \mathrm{mg} / \mathrm{kg}(\mathrm{F})$ of neopetasitenine for 90 days for humans. These human doses were taken from reported acute/short/long-term toxicity cases. A boy was exposed to a dose of $3 \mathrm{mg}$ pyrrolizidine alkaloids/kg body weight per day for 4 days with a lethal outcome. A girl was exposed to a dose of $0.8-1.7 \mathrm{mg}$ pyrrolizidine alkaloids/ $\mathrm{kg} / \mathrm{day}$ for 2 weeks and suffered hepatic veno-occlusive disease. The lowest known dose associated with long-term toxicity in humans is reported to be $15 \mu \mathrm{g}$ pyrrolizidine alkaloids/kg/day (exposure for a period of months) (EFSA, 2011). 


\section{Yanagi et al.}

an NADPH-generating system in a total of $0.20 \mathrm{~mL}$ of $100 \mathrm{mM}$ potassium phosphate buffer $(\mathrm{pH} 7.4)$ at $37^{\circ} \mathrm{C}$ for $15 \mathrm{~min}$. Linearity of substrate depletion rates was confirmed up to $2.0 \mathrm{mg}$ protein $/ \mathrm{mL}$ and $30 \mathrm{~min}$ incubation (results not shown).

Lactate dehydrogenase (LDH) leakage in the medium from the HepaRG cells [seeded onto 96 well-plate at a concentration of $5.0 \times 10^{5}$ cells $/ \mathrm{mL}$ (Murayama and Yamazaki, 2018)] incubated with neopetasitenine or petasitenine for $24 \mathrm{hr}$ was measured by the oxidation of NADH (Yamamoto et al., 2001) with an absorbance at $490 \mathrm{~nm}$, using a LDH assay kit commercially available (Dojindo Laboratories, Kumamoto, Japan). Carbamazepine was selected as a positive control as an index of cytotoxicity.

\section{Estimation of plasma concentrations using pharmacokinetic models}

Simplified rat PBPK models for neopetasitenine and petasitenine composed of chemical receptor (gut), metabolizing (liver), excreting (kidney), and central compartments were established as described elsewhere (Kamiya et al., 2020c; Miura et al., 2021). The values used for the hepatic and renal blood flow rates $\left(Q_{\mathrm{h}}\right.$ and $\left.Q_{\mathrm{r}}\right)$ in rats $(0.853 \mathrm{~L} / \mathrm{hr})$ and humans $(96.6 \mathrm{~L} / \mathrm{hr})$ and the hepatic and renal volumes $\left(V_{\mathrm{h}}\right.$ and $\left.V_{\mathrm{r}}\right)$ in rats $(8.5$ and $3.7 \mathrm{~mL}$ ) and humans $(1.5$ and $0.28 \mathrm{~L})$, respectively, were described previously (Kamiya et al., 2020a). Acid dissociation constants for the model substrates were estimated using ACD/Percepta software (Advanced Chemistry Development, Toronto, ON, Canada). The blood-to-plasma concentration ratio $\left(R_{\mathrm{b}}\right)$ and the liver-to-plasma and kidney-to-plasma concentration ratios $\left(K_{\mathrm{p}, \mathrm{h}}\right.$ and $\left.K_{\mathrm{p}, \mathrm{r}}\right)$ of the relevant compounds were estimated from the plasma unbound fraction $\left(f_{\mathrm{u}, \mathrm{p}}\right)$ and octanol-water partition coefficient $(\log P)$ values (Uchimura et al., 2010; Takano et al., 2010; Kamiya et al., 2019).

The initial parameter values for the PBPK model, i.e., the absorption rate constant $\left(k_{\mathrm{a}}\right)$, the volume of the systemic circulation $\left(V_{1}\right)$, and the hepatic intrinsic clearance $\left(C L_{\mathrm{h}, \mathrm{in}}\right)$, were estimated using in silico machine learning methods with a training dataset of 246 chemicals, as described previously (Kamiya et al., 2021). This was done because of the absence of experimental pharmacokinetic data in rats. Because urinary excretion data was also not available, the general ratios of $C L_{\mathrm{h}}$ to renal clearance $\left(C L_{\mathrm{r}}\right)$ were set at 9:1 for the substrates in rats. The fraction absorbed $\left(F_{\mathrm{a}}\right)$ was estimated based on the measured permeability across an experimental intestinal epithelial cell monolayer (Kamiya et al., 2020b). Intestinal availability $\left(F_{\mathrm{g}}\right)$ values were estimated from the gut extraction ratios as one-tenth of the hepatic extraction ratios $\left(E_{\mathrm{h}}\right)$ in the hepatic well-stirred model $\left(F_{\mathrm{g}}=1-E_{\mathrm{h}} / 10\right)$.

The concentrations of neopetasitenine and petasitenine in plasma from orally treated rats were determined. Based on the resulting experimental pharmacokinetic data in rats, in vivo pharmacokinetic parameters were primarily derived from the plasma concentration-time curves using one-compartmental analysis with Phoenix WinNonlin 8.2 (Pharsight, Mountain View, CA, USA). Primary initial values for the fraction absorbed $\times$ intestinal availability $\left(F_{\mathrm{a}} \cdot F_{\mathrm{g}}\right)$, the hepatic clearance $\left(C L_{h}=\frac{Q_{h} \cdot f_{u_{p}} \cdot C_{L_{h i n t}}}{Q_{h}+f_{u_{u}} \cdot C L_{h, i n t}}\right)$, and the renal clearance $\left(C L_{\mathrm{r}}\right)$ for the PBPK model were obtained from the elimination constants obtained using one-compartment models (Miura et al., 2021; Miura et al., 2020a). Then experimental $k_{\mathrm{a}}, V_{1}$, and $C L_{\mathrm{h}, \text { int }}$ values with standard deviations were established by fitting using nonlinear regression analyses.

The final parameter values for neopetasitenine and its metabolite petasitenine in rat PBPK models are shown in Tables 1 and 2. To calculate the chemical concentrations in the respective compartments of our PBPK model, the resulting set of differential equations was solved for concentrations of the substrate and its metabolite (indicated with subscript $m$ ):

$$
\begin{aligned}
& \frac{d X_{g}}{d t}=-k_{a} \cdot X_{g} \text { when at } t=0, X_{g}(0)=F \mathrm{a} \cdot F \mathrm{~g} \cdot \text { dose } \\
& V_{h} \frac{d C_{h}}{d t}=k_{a} \cdot X_{g}-\frac{Q_{h} \cdot C_{h} \cdot R_{b}}{K_{p, h}}-C L_{h, i n t} \cdot \frac{C_{h}}{K_{p, h}} \cdot f_{u, p}+Q_{h} \cdot C_{b} \\
& V_{1} \frac{d C_{b}}{d t}=-\left(Q_{h}+Q_{r}\right) \cdot C_{b}+\frac{Q_{h} \cdot C_{h} \cdot R_{b}}{K_{p, h}}+\frac{Q_{r} \cdot C_{r} \cdot R_{b}}{K_{p, r}} \\
& V_{r} \frac{d C_{r}}{d t}=Q_{r} \cdot C_{b}-\frac{Q_{r} \cdot C_{r} \cdot R_{b}}{K_{p, r}}-C L_{r} \cdot \frac{C_{r}}{K_{p, r}} \cdot f_{u, p} \\
& V_{h, m} \frac{d C_{h, m}}{d t}=Q_{h} \cdot C_{b, m}-\frac{Q_{h} \cdot C_{h, m} \cdot R_{b, m}}{K_{p, h, m}}+C L_{h, i n t} \cdot \frac{C_{h}}{K_{p, h}} \cdot f_{u, p}-C L_{h, i n t, m} \cdot \frac{C_{h, m}}{K_{p, h, m}} \cdot f_{u, p, m} \\
& V_{1, m} \frac{d C_{b, m}}{d t}=-\left(Q_{h}+Q_{r}\right) \cdot C_{b, m}+\frac{Q_{h} \cdot C_{h, m} \cdot R_{b, m}}{K_{p, h, m}}+\frac{Q_{r} \cdot C_{r, m} \cdot R_{b, m}}{K_{p, r, m}} \\
& V_{r, m} \frac{d C_{r, m}}{d t}=Q_{r} \cdot C_{b, m}-\frac{Q_{r} \cdot C_{r, m} \cdot R_{b, m}}{K_{p, r, m}}-C L_{r, m} \cdot \frac{C_{r, m}}{K_{p, r, m}} \cdot f_{u, p, m}
\end{aligned}
$$

where $X_{\mathrm{g}}, V_{\mathrm{h}}, V_{\mathrm{r}}, C_{\mathrm{h}}, C_{\mathrm{r}}$, and $C_{\mathrm{b}}$ are the amounts of compound in the gut compartment; the liver and kidney volumes; and the hepatic, renal, and blood substrate concentrations, respectively (Kamiya et al., 2020a).

To establish the human PBPK models of neopetasitenine and its metabolite petasitenine based on the rat PBPK model parameters, physiological parameters for humans were used. The $k_{\mathrm{a}}, V_{1}$, and $C L_{\mathrm{h}, \text { int }}$ values for neopetasitenine and petasitenine were estimated using a scale-up strategy from rats to humans. To obtain the human absorption rate constant $\left(k_{\mathrm{a}}\right)$, the $k_{\mathrm{a}}$ value in rats was multiplied by 0.744 . The systemic circulation volume in humans $\left(V_{1, \text { human }}\right)$ was estimated using $V_{\mathrm{h} \text {, human }}, V_{\mathrm{h} \text {, rat }}$, blood volume ( $V_{\mathrm{b} \text {, human }}$, $4.90 \mathrm{~L})$, and $V_{\mathrm{b} \text {, rat }}(0.0160 \mathrm{~L})$ :

$$
\begin{aligned}
& V_{s s, \text { human }}(\mathrm{L})=V_{s s, \text { rodent }}(\mathrm{L}) \cdot \frac{\text { Body weight }_{\text {human }}}{\text { Body weight }_{\text {rodent }}} \\
& V_{1}=\left(V_{s S}-V_{b}-V_{h} \cdot \frac{K_{p, h} \times F_{h}}{R_{b}}-V_{r} \cdot \frac{K_{p, r}}{R_{b}}\right) / \frac{f_{u, p}+1}{2}
\end{aligned}
$$


PBPK modeling of neopetasitenine in humans

Table 1. Chemical properties of neopetasitenine and petasitenine and paramters used for PBPK modeling estimated by in silico methods.

\begin{tabular}{|c|c|c|}
\hline & Neopetasitenine & Petasitenine \\
\hline \multicolumn{3}{|l|}{ Chemical properties } \\
\hline Molecular weight & 424 & 381 \\
\hline Octanol-water partition coefficient, $\log P$ & 0.511 & -0.173 \\
\hline Plasma unbound fraction & 0.860 & 0.752 \\
\hline Microsomal unbound fraction & 0.986 & 0.985 \\
\hline Blood-plasma concentration ratio & 0.754 & 0.826 \\
\hline Liver-plasma concentration ratio & 0.765 & 0.674 \\
\hline \multicolumn{3}{|l|}{ Parameters estimated by in silico methods } \\
\hline Apparent permeability (nm/sec) & $11.1(40.3)^{\mathrm{a}}$ & $11.3(18.4)^{\mathrm{a}}$ \\
\hline Apparent fraction absorbed & $0.565^{\mathrm{a}}$ & $0.589^{\mathrm{a}}$ \\
\hline Absorption rate constant, $k_{\mathrm{a}}(1 / \mathrm{hr})$ & $1.07^{\mathrm{b}}$ & $1.45^{\mathrm{b}}$ \\
\hline Volume of systemic circulation, $V_{1}(\mathrm{~L})$ & $1.32^{\mathrm{b}}$ & $2.03^{\mathrm{b}}$ \\
\hline Hepatic intrinsic clearance, $C L_{\mathrm{h}, \text { int, }}(\mathrm{L} / \mathrm{hr})$ & $0.273^{\mathrm{b}}$ & $0.226^{\mathrm{b}}$ \\
\hline
\end{tabular}

${ }^{a}$ Estimated apparent permeability by in silico descriptors (Kamiya et al., 2020b); the value in parentheses was determined experimentally and confirmed after the in silico estimation.

'Initial values for PBPK modeling for the absorption rate constant $\left(k_{\mathrm{a}}\right)$, volume of the systemic circulation $\left(V_{1}\right)$, and hepatic intrinsic clearance $\left(C L_{\mathrm{h}, \text { int }}\right)$ were estimated by in silico machine learning methods with a dataset of 246 chemicals, as described previously (Kamiya et al., 2021).

where $F_{\mathrm{h}}$ is the unmetabolized fraction in liver, $V_{\mathrm{ss}}$ is the steady-state volume of distribution, and $\frac{f_{u p}+1}{2}$ corresponds to the fraction unbound in tissue. To estimate the in vivo hepatic intrinsic clearance $\left(C L_{\mathrm{h}, \mathrm{int}}\right)$ in humans, the calculated initial parameters for in vitro hepatic intrinsic clearance in humans was multiplied by the ratio of in vivo to in vitro hepatic intrinsic clearance in rats. In vitro hepatic intrinsic clearances were calculated from the elimination rates of neopetasitenine and petasitenine using the liver microsomal unbound fractions determined using Simcyp software (Jamei et al., 2009). Estimation of the human renal clearance $C L_{\mathrm{r}, \mathrm{human}}$ was based on the equation

$$
C L_{r, \text { human }}=\frac{C L_{r, \text { rodent }}}{\text { Body weight }_{\text {rodent }}\left(\frac{2}{3}\right)} \cdot \text { Body weight }_{\text {human }}\left(\frac{2}{3}\right)
$$

where $\mathrm{BW}_{\text {rodent }}=0.25 \mathrm{~kg}$ (rat) and $\mathrm{BW}_{\text {human }}=70 \mathrm{~kg}$. The final values of the PBPK model parameters for humans are given in Table 2. The above-described set of differential equations was solved to calculate the concentrations in the respective body compartments in humans.

\section{RESULTS AND DISCUSSION}

Neopetasitenine (Kitajima et al., 2019) is one of the most abundant pyrrolizidine alkaloids in P. japonicus (https://www.maff.go.jp/j/press/syouan/nouan/attach/ pdf/180831-1.pdf, 2018). However, the toxicological potential of neopetasitenine has not been clarified. In this study, neopetasitenine and its deacetylated metabo- lite petasitenine were selected as model substances. The previously reported in silico machine learning system (Kamiya et al., 2021) yielded important pharmacokinetic parameters $\left(k_{\mathrm{a}}, V_{1}\right.$, and $\left.C L_{\mathrm{h}, \mathrm{in}}\right)$ of neopetasitenine and petasitenine based on their chemical descriptors (Table 1). This approach was used because of the absence of experimental pharmacokinetic data in rats. The above pharmacokinetic parameters completed the input values needed to run the PBPK model, thereby allowing virtual plasma concentration profiles to be generated for rats. The resulting in silico plasma concentration curves for neopetasitenine and petasitenine versus time after virtual single oral doses of $1.0 \mathrm{mg} / \mathrm{kg}$ in rats are indicated in Fig. 1B and 1C. The rat PBPK models predicted mean plasma concentrations of neopetasitenine and petasitenine in the 24-hr period (area under the curves divided by $24 \mathrm{hr}$ ) after virtual oral doses of $1.0 \mathrm{mg} / \mathrm{kg}$ to be 22 and $29 \mathrm{ng} / \mathrm{mL}$, respectively. These concentration levels were estimated to be quantitatively measurable using LC analyses; consequently, pharmacokinetic studies in rats were conducted in which plasma levels were measured after the administration of neopetasitenine or petasitenine at the modeled dose of $1.0 \mathrm{mg} / \mathrm{kg}$.

Although low gut permeability was predicted by in silico descriptors (Table 1), neopetasitenine was rapidly absorbed and converted to deacetylated petasitenine after oral administration of $1.0 \mathrm{mg} / \mathrm{kg}$ in rats (Fig. 1B). In contrast, petasitenine was slowly cleared from rat plasma after oral administration of $1.0 \mathrm{mg} / \mathrm{kg}$ (Fig. 1C). Pharma- 
M. Yanagi et al.

Table 2. Experimental and final calculated parameters for rat one-compartment model and rat and human PBPK models for neopetasitenine and petasitenine based on rat pharmacokinetic data.

\begin{tabular}{|c|c|c|c|}
\hline Parameter & Abbreviation (unit) & \multicolumn{2}{|c|}{ Species } \\
\hline One-compartment model & \multicolumn{3}{|c|}{ Rat } \\
\hline Absorption rate constant for neopetasitenine & $1 / \mathrm{hr}$ & $2.89 \pm 0.53^{\mathrm{a}}$ & \\
\hline Absorption rate constant for petasitenine & $1 / \mathrm{hr}$ & $2.68 \pm 1.19^{\mathrm{a}}$ & \\
\hline Volume of distribution/bioavailability for neopetasitenine & $\mathrm{L} / \mathrm{kg}$ & $4.06 \pm 0.71^{\mathrm{a}}$ & \\
\hline Volume of distribution for petasitenine & $\mathrm{L} / \mathrm{kg}$ & $1.44 \pm 0.26^{\mathrm{a}}$ & \\
\hline Oral clearance for neopetasitenine & $\mathrm{L} / \mathrm{hr} / \mathrm{kg}$ & $9.81 \pm 0.75^{\mathrm{a}}$ & \\
\hline Oral clearance for petasitenine & $\mathrm{L} / \mathrm{hr} / \mathrm{kg}$ & $1.04 \pm 0.01^{\mathrm{a}}$ & \\
\hline PBPK model & & Rat & Human \\
\hline Fraction absorbed $\times$ intestinal availability & $F_{\mathrm{a}} \cdot F_{\mathrm{g}}$ & 0.559 & 0.559 \\
\hline Absorption rate constant for neopetasitenine & $k_{\mathrm{a}}(1 / \mathrm{hr})$ & $5.72 \pm 0.08^{\mathrm{b}}$ & 4.25 \\
\hline Volume of systemic circulation for neopetasitenine & $V_{1 \_ \text {substrate }}(\mathrm{L})$ & $0.413 \pm 0.024^{\mathrm{b}}$ & 116 \\
\hline Hepatic intrinsic clearance for neopetasitenine & $C \bar{L}_{\mathrm{h}, \text { int } \_ \text {substrate }}(\mathrm{L} / \mathrm{hr})$ & $1.33 \pm 0.06^{\mathrm{b}}$ & 200 \\
\hline Hepatic clearance for neopetasitenine & $C L_{\mathrm{h}, \text { substrate }}(\mathrm{L} / \mathrm{hr})$ & 0.489 & 61.9 \\
\hline Renal clearance for neopetasitenine & $C L_{\mathrm{r}, \text { substrate }}(\mathrm{L} / \mathrm{hr})$ & 0.055 & 2.35 \\
\hline Volume of systemic circulation for petasitenine & $V_{1 \_ \text {metabolite }}(\mathrm{L})$ & $0.501 \pm 0.028^{\mathrm{b}}$ & 141 \\
\hline Hepatic intrinsic clearance for petasitenine & $C \bar{L}_{\mathrm{h}, \text { int_metabolite }}(\mathrm{L} / \mathrm{hr})$ & $0.118 \pm 0.011^{\mathrm{b}}$ & 17.7 \\
\hline Hepatic clearance for petasitenine & $C L_{\mathrm{h}_{-} \text {metabolite }}(\mathrm{L} / \mathrm{hr})$ & 0.081 & 11.7 \\
\hline Renal clearance for petasitenine & $C L_{r_{-} \text {metabolite }}(\mathrm{L} / \mathrm{hr})$ & 0.065 & 2.78 \\
\hline \multicolumn{4}{|l|}{ Estimated values } \\
\hline $\mathrm{C}_{\max }$ in plasma for neopetasitenine & $\mathrm{ng} / \mathrm{mL}$ & $100(1.0)^{\mathrm{c}}$ & \\
\hline AUC in plasma for neopetasitenine & ng hr/mL & $109(0.86)^{\mathrm{c}}$ & \\
\hline $\mathrm{C}_{\max }$ in plasma for petasitenine & $\mathrm{ng} / \mathrm{mL}$ & $21(1.3)^{\mathrm{c}}$ & \\
\hline AUC in plasma for petasitenine & ng hr/mL & $86(1.3)^{\mathrm{c}}$ & \\
\hline \multicolumn{4}{|l|}{ Observed levels } \\
\hline $\mathrm{C}_{\max }$ in plasma for neopetasitenine & $\mathrm{ng} / \mathrm{mL}$ & 98 & \\
\hline AUC in plasma for neopetasitenine & $\mathrm{ng} \mathrm{hr} / \mathrm{mL}$ & 127 & \\
\hline $\mathrm{C}_{\max }$ in plasma for petasitenine & $\mathrm{ng} / \mathrm{mL}$ & 16 & \\
\hline AUC in plasma for petasitenine & $\mathrm{ng} \mathrm{hr} / \mathrm{mL}$ & 65 & \\
\hline
\end{tabular}

aData are means \pm standard deviations for three individual rat pharmacokinetics. ${ }^{b}$ Data are means \pm standard deviations of fitting estimations. "Estimated outputs; values in parentheses are ratios to the observed values. AUC, area under the concentration curve from 0 to $8 \mathrm{hr}$. The metabolic ratio to petasitenine was 0.1 for the hepatic intrinsic clearance for rats and humans by parameter fitting. When petasitenine was orally administered to rats, its absorption rate constant in the rat PBPK petasitenine model was calculated to be $6.68 \pm 0.291 / \mathrm{hr}$. Parameters such as $K_{\mathrm{p}, \mathrm{h}}, K_{\mathrm{p}, \mathrm{r}}, R_{\mathrm{b}}$, and $f_{\mathrm{u}, \mathrm{p}}$ were assumed to be the same for humans and for rats.

cokinetic parameters such as $k_{\mathrm{a}}$, the apparent volume of distribution $(V / F)$, and the oral clearance $(C L)$ were preliminary calculated for neopetasitenine and petasitenine using one-compartment models (Table 2), based on the rat plasma data obtained in the present study. Under the present conditions, experimentally determined parameters for rat PBPK modeling, i.e., $k_{\mathrm{a}}, V_{1}$, and $C L_{\mathrm{h}, \text { int }}$, were calculated based on the plasma data measured in the present study and are shown in Table 2. By solving the equations that constitute the PBPK models, estimated plasma concentration curves were generated for rats; the modeled in silico concentration curves are shown in Fig. 1B and 1C. Because the values in rat plasma of maximum concentration $\left(\mathrm{C}_{\max }\right)$ and the area under the concentration curve from $0-8 \mathrm{hr}$ after administrations (AUC) of neopetasitenine and petasitenine extrapolated using the rat PBPK models (Table 2) were consistent (within roughly 1.3-fold) with the experimentally observed values in rats (Fig. 1B and 1C), the current PBPK models were considered to reasonably reflect the observed in vivo plasma data. After virtual administration of single oral doses of $1.0 \mathrm{mg} / \mathrm{kg}$ neopetasitenine in rats, the plasma concentrations of the metabolite petasitenine were almost always (i.e., from $\sim 2 \mathrm{hr}$ after administration) higher than those of the substrate neopetasitenine (Fig. 1B).

To establish human PBPK models for neopetasitenine and its metabolite petasitenine, the in vitro substrate elimination rates were examined in experimental systems con- 
PBPK modeling of neopetasitenine in humans

taining liver microsomes or liver S9 fractions from rats and humans. The rat and human in vitro hepatic intrinsic clearances for neopetasitenine were evaluated based on the elimination rates in liver microsome ( 35 and $43 \mu \mathrm{L} /$ $\mathrm{min} / \mathrm{mg}$ microsomal protein, respectively) and on the liver S9 elimination rates $(4.5$ and $5.6 \mu \mathrm{L} / \mathrm{min} / \mathrm{mg}$ S9 protein, respectively). The rat and human in vitro deacetylation rates for neopetasitenine by liver microsomes were 2.0 and $3.3 \mu \mathrm{L} / \mathrm{min} / \mathrm{mg}$ microsomal protein, respectively. The in vitro hepatic intrinsic clearance values observed for petasitenine in rats and humans were similar (8.1 and $7.4 \mu \mathrm{L} / \mathrm{min} / \mathrm{mg}$ microsomal protein). With the present results indicating roughly similar elimination rates for neopetasitenine and its metabolite petasitenine, an allometric scaling approach was applied without consideration of any interspecies factors to estimate intrinsic hepatic clearances in humans based on those in rats. Using this approach, parameters for the human PBPK model were established for neopetasitenine and its metabolite petasitenine (Table 2).

Plasma concentration curves after multiple virtual administrations of neopetasitenine in humans were generated by the PBPK model with the newly established human parameters. Figure 1D and 1E show the modeled plasma and hepatic concentration curves for neopetasitenine and its metabolite petasitenine after daily oral administrations of 3.0 or $1.3 \mathrm{mg} / \mathrm{kg}$ neopetasitenine in humans (70 kg body weight); these doses were taken from reports of acute/short-term toxicity cases. In the acute case, a boy was exposed to $3 \mathrm{mg}$ pyrrolizidine alkaloids/kg body weight per day for 4 days, with a lethal outcome. In the short-term toxicity case, a girl was exposed to $0.8-1.7 \mathrm{mg}$ pyrrolizidine alkaloids/kg/day for a 2 -week period and suffered hepatic veno-occlusive disease (EFSA, 2011). Because the reported lowest known dose associated with long-term toxicity in humans was to be $15 \mu \mathrm{g}$ pyrrolizidine alkaloids/kg/day (EFSA, 2011), Fig. 1F shows the modeled plasma and hepatic concentration curves for neopetasitenine and petasitenine after daily oral administrations of $0.015 \mathrm{mg} / \mathrm{kg}$ neopetasitenine in humans for 90 days. The mean plasma concentrations of neopetasitenine and petasitenine on the 4th day of daily oral administrations of $3.0 \mathrm{mg} / \mathrm{kg}$ were estimated to be 27 and $30 \mathrm{ng} / \mathrm{mL}$, respectively, in the former lethal-outcome case. Similarly, in the short- and long-term toxicity cases, the mean plasma concentrations of neopetasitenine and petasitenine on the 14th and 90th day of daily oral administrations of 1.3 and $0.015 \mathrm{mg} / \mathrm{kg}$ were estimated to be 12 and $13 \mathrm{ng} / \mathrm{mL}$ and $\sim 0.1$ and $\sim 0.1 \mathrm{ng} / \mathrm{mL}$, respectively, resulting in cases of hepatic veno-occlusive disease. There was apparent linearity in the estimated plasma concentrations of neo-

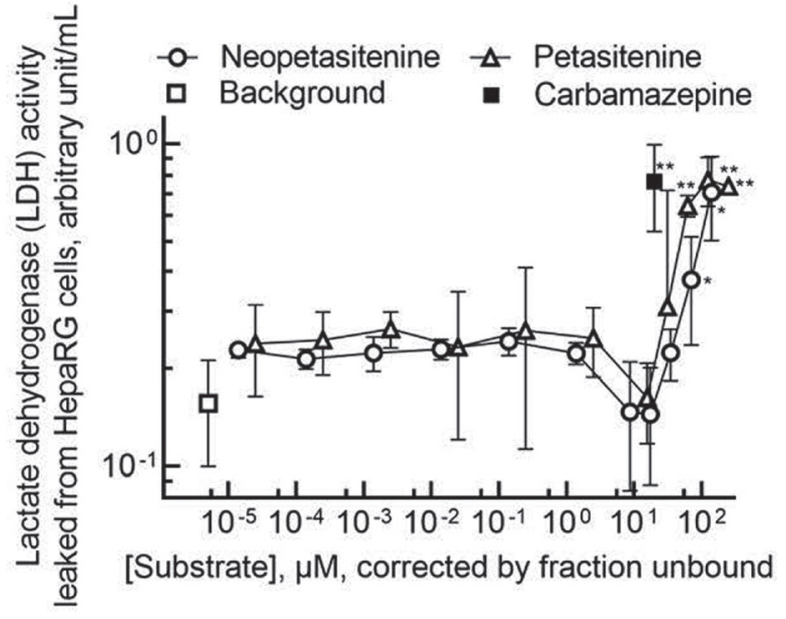

Fig. 2. Lactate dehydrogenase (LDH) activity in the medium leaked from the HepaRG cells incubated with neopetasitenine or petasitenine. Values are mean $\pm \mathrm{SD}$ of three individual experiments. ${ }^{* *} p<0.01$ and $* p<0.05$, compared with background control values by unpaired $t$-test.

petasitenine and petasitenine in these three cases over 4-day, 2-week, and 3-month periods.

The LDH leakages after treatment with neopetasitenine and petasitenine in the HepaRG cells, a human hepatocyte-like cell line, are shown in Fig. 2. Neopetasitenine and petasitenine caused low but significant LDH leakage ( $p<0.05$ and $p<0.01$ ), as compared with the background control (Fig. 2), in the dose-dependent manner.

In conclusions, in the present study, forward dosimetry assessments of plasma levels of the pyrrolizidine alkaloid neopetasitenine and its metabolite petasitenine were conducted by creating a human PBPK neopetasitenine model (following our simplified modeling strategy) based on a rat PBPK neopetasitenine model that was established using in vivo rodent pharmacokinetic data. To generate the human PBPK model parameters, allometric scaling was applied to rat PBPK parameters with no consideration of any potential interspecies factors. Following this approach, the intrinsic hepatic clearances in humans was estimated based on those in rats. Neopetasitenine (acetylfukinotoxin) was estimated to be rapidly absorbed and converted to deacetylated carcinogenic petasitenine (fukinotoxin) even after a hepatotoxic dose of $1.0 \mathrm{mg} / \mathrm{kg}$ in humans. The toxicological potential of neopetasitenine has not yet been fully clarified, despite the in vitro hepatotoxicity caused by its high concentrations in human hepatocyte-like cell line HepaRG cells (Fig. 2). However, if the water-soluble pyrrolizidine alkaloid-pro- 


\section{Yanagi et al.}

ducing plant $P$. japonicus were to be consumed daily as a wild food vegetable, the current PBPK simulations suggest that dangerous concentrations of deacetylated petasitenine could be continuously present in human plasma or livers.

\section{ACKNOWLEDGMENTS}

The authors thank Drs. Takashi Yamada, Fumiaki Shono, Masato Kitajima, Akiko Toda, Asuka Omura, Shiori Hina, and Kazuki Shigeta for their assistance and David Smallbones for copyediting a draft of this article. This work was supported in part by the Food Safety Commission of Japan (JPCAFSC20202006) and the METI Artificial Intelligence-based Substance Hazard Integrated Prediction System Project, Japan.

Conflict of interest---- The authors declare that there is no conflict of interest.

\section{REFERENCES}

Chen, T., Mei, N. and Fu, P.P. (2010): Genotoxicity of pyrrolizidine alkaloids. J. Appl. Toxicol., 30, 183-196.

EFSA. (2011): Scientific opinion on pyrrolizidine alkaloids in food and feed. EFSA J., 9, 2406.

Hirono, I., Haga, M., Fujii, M., Matsuura, S., Matsubara, N., Nakayama, M., Furuya, T., Hikichi, M., Takanashi, H., Uchida, E., Hosaka, S. and Ueno, I. (1979): Induction of hepatic tumors in rats by senkirkine and symphytine. J. Natl. Cancer Inst., 63, 469-472.

Hirono, I., Mori, H., Yamada, K., Hirata, Y. and Haga, M. (1977): Carcinogenic activity of petasitenine, a new pyrrolizidine alkaloid isolated from Petasites japonicus Maxim. J. Natl. Cancer Inst., 58, 1155-1157.

Jamei, M., Marciniak, S., Feng, K., Barnett, A., Tucker, G. and Rostami-Hodjegan, A. (2009): The Simcyp population-based ADME simulator. Expert Opin. Drug Metab. Toxicol., 5, 211-223.

Kamiya, Y., Handa, K., Miura, T., Yanagi, M., Shigeta, K., Hina, S., Shimizu, M., Kitajima, M., Shono, F., Funatsu, K. and Yamazaki, H. (2021): In silico prediction of input parameters for simplified physiologically based pharmacokinetic models for estimating plasma, liver, and kidney exposures in rats after oral doses of 246 disparate chemicals. Chem. Res. Toxicol., 34, 507-513.

Kamiya, Y., Otsuka, S., Miura, T., Takaku, H., Yamada, R., Nakazato, M., Nakamura, H., Mizuno, S., Shono, F., Funatsu, K. and Yamazaki, H. (2019): Plasma and hepatic concentrations of chemicals after virtual oral administrations extrapolated using rat plasma data and simple physiologically based pharmacokinetic models. Chem. Res. Toxicol., 32, 211-218.

Kamiya, Y., Otsuka, S., Miura, T., Yoshizawa, M., Nakano, A., Iwasaki, M., Kobayashi, Y., Shimizu, M., Kitajima, M., Shono, F., Funatsu, K. and Yamazaki, H. (2020a): Physiologically based pharmacokinetic models predicting renal and hepatic concentrations of industrial chemicals after virtual oral doses in rats. Chem. Res. Toxicol., 33, 1736-1751.

Kamiya, Y., Takaku, H., Yamada, R., Akase, C., Abe, Y., Sekiguchi,
Y., Murayama, N., Shimizu, M., Kitajima, M., Shono, F., Funatsu, K. and Yamazaki, H. (2020b): Determination and prediction of permeability across intestinal epithelial cell monolayer of a diverse range of industrial chemicals/drugs for estimation of oral absorption as a putative marker of hepatotoxicity. Toxicol. Rep., 7, 149-154.

Kamiya, Y., Yanagi, M., Hina, S., Shigeta, K., Miura, T. and Yamazaki, H. (2020c): Plasma, liver, and kidney exposures in rats after oral doses of industrial chemicals predicted using physiologically based pharmacokinetic models: A case study of perfluorooctane sulfonic acid. J. Toxicol. Sci., 45, 763-767.

Kitajima, M., Okabe, K., Yoshida, M., Nakabayashi, R., Saito, K., Kogure, N. and Takayama, H. (2019): New otonecine-type pyrrolizidine alkaloid from Petasites japonicus. J. Nat. Med., 73, 602-607.

Kiyoyuki, Y., Hiroshi, T., Masaaki, S., Yoshimasa, H., Masanobu, H. and Iwao, H. (1976): Isolation and the structures of two new alkaloids, petasitenine and neopetasteinine from Petasites japonica Maxim. Chem. Lett., 5, 461-464.

Miura, T., Kamiya, Y., Hina, S., Kobayashi, Y., Murayama, N., Shimizu, M. and Yamazaki, H. (2020a): Metabolic profiles of coumarin in human plasma extrapolated from a rat data set with a simplified physiologically based pharmacokinetic model. J. Toxicol. Sci., 45, 695-700.

Miura, T., Shimizu, M., Uehara, S., Yoshizawa, M., Nakano, A., Yanagi, M., Kamiya, Y., Murayama, N., Suemizu, H. and Yamazaki, H. (2020b): Different hepatic concentrations of bromobenzene, 1,2-dibromobenzene, and 1,4-dibromobenzene in humanized-liver mice predicted using simplified physiologically based pharmacokinetic models as putative markers of toxicological potential. Chem. Res. Toxicol., 33, 3048-3053.

Miura, T., Uehara, S., Mizuno, S., Yoshizawa, M., Murayama, N., Kamiya, Y., Shimizu, M., Suemizu, H. and Yamazaki, H. (2019a): Steady-state human pharmacokinetics of monobutyl phthalate predicted by physiologically based pharmacokinetic modeling using single-dose data from humanized-liver mice orally administered with dibutyl phthalate. Chem. Res. Toxicol., 32, 333-340.

Miura, T., Uehara, S., Nakazato, M., Kusama, T., Toda, A., Kamiya, Y., Murayama, N., Shimizu, M., Suemizu, H. and Yamazaki, H. (2019b): Human plasma and liver concentrations of styrene estimated by combining a simple physiologically based pharmacokinetic model with rodent data. J. Toxicol. Sci., 44, 543-548.

Miura, T., Uehara, S., Shimizu, M., Suemizu, H. and Yamazaki, H. (2021): Pharmacokinetics of primary oxidative metabolites of thalidomide in rats and in chimeric mice humanized with different human hepatocytes. J. Toxicol. Sci., 46, 311-317.

Murayama, N. and Yamazaki, H. (2018): Cytochrome P450-dependent drug oxidation activities in commercially available hepatocytes derived from human induced pluripotent stem cells cultured for 3 weeks. J. Toxicol. Sci., 43, 241-245.

Neuman, M.G., Cohen, L., Opris, M., Nanau, R.M. and Hyunjin, J. (2015): Hepatotoxicity of pyrrolizidine alkaloids. J. Pharm. Pharm. Sci., 18, 825-843.

Rietjens, I.M., Boersma, M.G., Zaleska, M. and Punt, A. (2008): Differences in simulated liver concentrations of toxic coumarin metabolites in rats and different human populations evaluated through physiologically based biokinetic (PBBK) modeling. Toxicol. In Vitro, 22, 1890-1901.

Sweeney, L.M., Kirman, C.R., Gargas, M.L., Carson, M.L. and Tardiff, R.G. (2010): Development of a physiologically-based toxicokinetic model of acrylamide and glycidamide in rats and 
PBPK modeling of neopetasitenine in humans

humans. Food Chem. Toxicol., 48, 668-685.

Takano, R., Murayama, N., Horiuchi, K., Kitajima, M., Kumamoto, M., Shono, F. and Yamazaki, H. (2010): Blood concentrations of acrylonitrile in humans after oral administration extrapolated from in vivo rat pharmacokinetics, in vitro human metabolism, and physiologically based pharmacokinetic modeling. Regul. Toxicol. Pharmacol., 58, 252-258.

Uchimura, T., Kato, M., Saito, T. and Kinoshita, H. (2010): Prediction of human blood-to-plasma drug concentration ratio. Biopharm. Drug Dispos., 31, 286-297.

Vassallo, J.D., Hicks, S.M., Daston, G.P. and Lehman-McKeeman,
L.D. (2004): Metabolic detoxification determines species differences in coumarin-induced hepatotoxicity. Toxicol. Sci., 80, 249-257.

Wang, C., Li, Y., Gao, J., He, Y., Xiong, A., Yang, L., Cheng, X., Ma, Y. and Wang, Z. (2011): The comparative pharmacokinetics of two pyrrolizidine alkaloids, senecionine and adonifoline, and their main metabolites in rats after intravenous and oral administration by UPLC/ESIMS. Anal. Bioanal. Chem., 401, 275-287.

Yamamoto, Y., Nakajima, M., Yamazaki, H. and Yokoi, T. (2001): Cytotoxicity and apoptosis produced by troglitazone in human hepatoma cells. Life Sci., 70, 471-482. 